\title{
Videoscopic study of deep-sea hydrothermal vent alvinellid polychaete populations: biomass estimation and behaviour
}

\author{
P. Chevaldonné, D. Jollivet \\ Département Environnement Profond, IFREMER Centre de Brest, BP 70, F-29280 Plouzané, France
}

\begin{abstract}
Biomass is a poorly documented parameter of the hydrothermal ecosystem, partly due to the difficulties in estimating it. Because the hydrothermal alvinellid polychaete worms mostly live in tubes, and on very irregular surfaces difficult to sample, an original biomass estimation method based on video analysis was proposed and tested on populations of the East Pacific Rise at $13^{\circ} \mathrm{N}$. The area covered by the 3 main alvinellid species was accurately estimated from geometrical calculations in oblique-angle conditions, requiring only 3 object measurements on the monitor screen. The total density of alvinellids was estimated on video by modelling the pattern of worm movements in and out of their tubes. The Richards function was found appropriate to model the resulting asymptotic curves. Biomass was calculated from mean alvinellid weights for populations from 3 white smokers and 1 black smoker. Values ranged from 10.7 to $70.1 \mathrm{~g}$ ash-free dry weight $\mathrm{m}^{-2}$, which is a much lower estimate than in previous studies, perhaps because of differences in sample size, sampling methods and the heterogeneity of studied assemblages. It was possible to discriminate Alvinella spp. from Paralvinella grasslei on the video because of differences in behaviour, allowing separate biomass calculations. Spatial variability of the alvinellid biomass was assessed for one chimney. Biomass was maximal at the top and the base, and minimal in the middle. Coverage of the chimney by the alvinellid tubes was spatially heterogeneous, and the genera displayed different distribution patterns. $P$. grasslei seems to move a lot and settle on chimneys in an opportunistic way, while Alvinella spp., more dependent on the environmental conditions, settle at the base and gradually move upwards as the chimney grows.
\end{abstract}

\section{INTRODUCTION}

Early descriptions of hydrothermal vent communities reported very high densities and biomasses of animals (Lonsdale 1977, Corliss et al. 1979, Spiess et al. 1980). These initial estimates appeared to be comparable to or even higher than those of the most productive benthic communities known at the time, such as coral reefs, shallow water mussel beds or kelp 'forests' (Fustec et al. 1988, Laubier 1989). Studies on hydrothermal ecology rarely refer to biomass, because this very important parameter is difficult to assess accurately. Childress (in Somero et al. 1983) estimated Riftia pachyptila clumps to be in the range of 10 to $15 \mathrm{~kg} \mathrm{~m}^{-2}$ (wet wt), while Hessler \& Smithey (1983) reported a $10.1 \mathrm{~kg} \mathrm{~m}^{-2}$ (wet wt) value for Bathymodiolus thermophilus beds in the Galapagos vents. Brault et al. (1985) present additional data for serpulid worms $(80 \mathrm{~g}$ $\mathrm{m}^{-2}$ wet $\left.\mathrm{wt}\right)$ and alvinellid polychaetes $\left(16 \mathrm{~kg} \mathrm{~m}^{-2}\right.$ wet wt with tubes), the latter value corresponding to a surprisingly high density of 300 individuals on a $30 \mathrm{~cm}$ long fragment of chimney (diameter $15 \mathrm{~cm}$ ). Fustec et al. (1988) attempted to quantify the biomass of the main trophic groups at 2 hydrothermal sites on the East Pacific Rise at $13^{\circ} \mathrm{N}$ (hereafter $13^{\circ} \mathrm{N} / \mathrm{EPR}$ ). Based on their estimates, primary consumers represent a wet biomass of 2.2 to $8 \mathrm{~kg} \mathrm{~m}^{-2}$, carnivores 0.17 to $0.45 \mathrm{~kg}$ $\mathrm{m}^{-2}$ and detritus feeders 0.028 to $0.080 \mathrm{~kg} \mathrm{~m}^{-2}$.

However, vent sites are characterized by irregular topography and extreme patchiness of animal distribution, therefore no reliable quantitative sampling techniques are yet available. Problems in biomass determination arise when estimating the surface sampled because (1) this surface is rarely flat, and any measurement requires scaling and accurate knowledge of the optical conditions of the photograph, (2) sampling is usually non-random and (3) the sampled surface varies greatly with the size and behaviour of the collected an- 
imals. For these reasons, references to biomass estimates of megafauna associated with vents are vague and often ambiguous.

Most members of the polychaete family Alvinellidae, only known from deep-sea hot vents (Desbruyères \& Laubier 1991), live in the hottest part of the hydrothermal environment. In some of the known vent areas (mainly the EPR), these worms appear to be the main biomass contributors on moderate- to high-temperature chimneys with fluid temperatures up to $350^{\circ} \mathrm{C}$ (Fustec et al. 1988). These chimneys are designated black or white smokers, according to their general appearance and the colour of the emitted fluid. On the EPR at $13^{\circ} \mathrm{N}, 4$ alvinellid species have been described: Alvinella pompejana, A. caudata, Paralvinella grasslei and $P$. pandorae irlandei (Desbruyères \& Laubier 1980. 1982, 1986). Both Alvinella species, dependent on high temperature emissions, live in white chitinous tubes built at the surface of smokers where they are the dominant megafaunal species. P. grasslei, usually smaller in size than Alvinella spp., produces mucous tubes in more diverse habitats, ranging from the tubes of Riftia pachyptila to Alvinella spp. populations. P. p. irlandei is even smaller and is rare in the smoker habitat. It is found more often at the base of tubes of the vestimentiferan Tevnia jerichonana.

Evaluation of alvinellid biomass from direct observation is not possible because the worms frequently remain retracted inside their tubes. When observed, only a few of the individuals are visible at a time, which makes instantaneous counting impossible. Counting tubes does not provide a valuable estimate either, as a substantial fraction of the tubes are empty. Quantitative sampling from submersibles is too poor to produce good estimates, but it was until now the only way to obtain preliminary alvinellid biomass data (Fustec et al. 1988).

A new procedure based on video analysis was investigated to improve upon the low reliability of sampling with submersible mechanical arms, and to take into account the variability of alvinellid population structure, differences in ecological conditions, and worms' behaviour. First, we could measure surfaces accurately by adapting standard geometrical calculations to the submersible's camera characteristics and to the alvinellids' environment. Secondly, we could estimate the total number of individuals living on these surfaces, by observing and modelling the alvinellids' behaviour.

\section{MATERIALS AND METHODS}

Material was collected during the French-American 'Hydronaut' cruise at $13^{\circ} \mathrm{N} / \mathrm{EPR}$ in November 1987. The submersible 'Nautile' has 2 mechanical arms, one of which is designed to grab samples. Maximal surface coverage by the grab is $0.065 \mathrm{~m}^{2}$. Samples were used for a direct comparison with the video estimates and to provide valuable biometrical data. The 'Nautile' is fitted with 2 video cameras, one of which, a colour TriCCD camera, was used for the analysis. This camera, located at the front of the submersible, looks forward at a downward angle of $45^{\circ}$ to the horizontal.

Surface estimation. Estimates of the surface area covered by alvinellid populations were based on geometrical calculations using the camera's characteristics (focal length, aperture angle) and the difference in refraction index between air and seawater. These techniques have commonly been used for transect analysis, where parameters such as angle and distance are required a priori and do not change from frame to frame (Bourgoin et al. 1985, Rice \& Collins 1985). The method used in this study does not take optical aberrations and distortions into account, but provides estimations in oblique-angle conditions that require only 3 on-screen measurements. Optical parameters (angle and distance) may change from frame to frame and are not required prior to calculation. This method, however, does not work for transect analysis as video sequences must be carefully chosen.

Being extremely irregular in shape, hydrothermal structures have to be decomposed into multiple surfaces, the dimensions of which are then estimated using measurements of objects lying on each plane. These reference objects must be centred, large enough to allow measurements on screen and their actual size must either be known, or, with organisms, estimated from the population's mean size.

Surface area $(S)$ is calculated using the formula describing the distortion of a rectangular surface into a trapezium under oblique-angle conditions (Fig. 1):

$$
S=\frac{4 D^{2} \cos ^{3} \theta \cos ^{3}(\alpha / 2) \sin (\alpha / 2) \operatorname{tg}(\beta / 2)}{\cos ^{2}(\theta-\alpha / 2) \cos ^{2}(\theta+\alpha / 2)}
$$

where $D=$ lens-to-object distance; $\theta=$ angle of incidence; $\alpha$ and $\beta$ =vertical and horizontal aperture angles of the camera; $\operatorname{tg}=$ tangent. As the 'Nautile' was not fitted with in situ measuring devices such as a laser distance-meter or stereovideo cameras, $D$ and $\theta$ had to be estimated. This was accomplished using pairs of perpendicular virtual measurements $l_{x}$ (horizontal axis) and $l_{y}$ (vertical axis), linked by an isometry ratio $R$ of a centred object of known size (characterized by $L_{x}$ and $\left.L_{y}\right) . D$ and $\theta$ are then estimated as follows:

$$
\begin{gathered}
D=f L_{x} / l_{x} \\
\cos \theta=\frac{2 f^{2}-\sqrt{4 f^{4}-l_{y}^{2}\left(4 f^{2-} l_{y e}{ }^{2}\right)}}{l_{y} l_{y e}}
\end{gathered}
$$




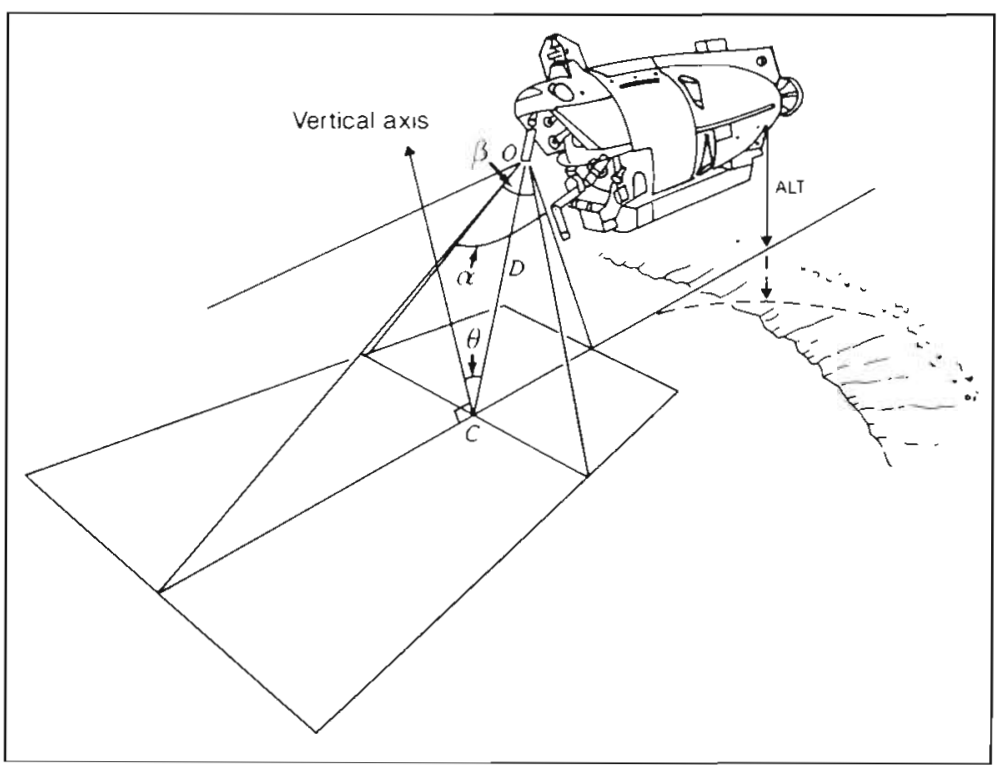

Fig. 1 Schematic representation of the submersible 'Nautile' and of the geometrical figures used to estimate surfaces from video images. $O$ : origin; $D$ : lens-to-object distance; $\theta$ : angle of incidence; $\alpha$ : vertical aperture angle of the camera; $\beta$ : horizontal aperture angle of the camera; $C$ : image centre; ALT.: altitude

where $f=$ focal length; $l_{\text {ye }}=$ the $l_{y}$ value expected using the isometry ratio $\left(l_{y \mathrm{e}}=R l_{x}\right)$. When the object axes are not parallel to the screen axes, the orientation angle is noted to allow corrections of estimates. This method was tested with the submersible's camera in an experimental seawater tank and proved to be very efficient as the linear correlation coefficients between experimental and expected values were very high $(\mathrm{r}>0.99)$ (Jollivet unpubl.).

To obtain the isometry ratio, the brachyuran crab Bythograea thermydron, frequently observed on alvinellid tubes and extensively sampled, was a particularly good subject. We estimated the cephalothorax length/width relationship from a regression line ( $a=$ $0.54 ; b=0.88 ; R^{2}>0.99$ ) obtained from measurements of 100 individuals ranging from 11 to $64 \mathrm{~mm}$ width. Adult crabs belonged to a single size group (modal length: $25.0 \mathrm{~mm}$; SD: $0.25 \mathrm{~mm}$ ). The size of crabs seen on the video recordings was estimated by this modal length. The distance $D$ is therefore subject to both errors in the actual size of the crabs compared with modal size ( 2 to $4 \%$ ), and in the accuracy of the measurements on screen, which varies with the distance ( 5 to $10 \%$ ).

Estimation of total number of alvinellid individuals on a given surface. Four video sequences of alvinellid populations from the Hydronaut cruise video collection were examined from the following sites: Elsa (10 min), Parigo (9 min), Totem (15 min) and Dallas (12 min). At timed intervals $(30 \mathrm{~s}$ at Dallas and Parigo, $20 \mathrm{~s}$ at
Totem, $10 \mathrm{~s}$ at Elsa) the number of individuals showing branchial crowns was noted (different time-intervals were tested, depending on the characteristics of the populations). Each individual worm was assigned a position on the screen of the video monitor, to identify every new worm appearance. We assumed that each worm had to emerge from time to time. Similar to the principle of rarefaction curves in which the species number approaches an asymptote as the sample size increases (Sanders 1968), it was further assumed that, by increasing the observation duration, the number of individual worms should tend to equal the actual total number of worms living on the observed surface. This number was divided by the surface area to obtain densities. The asymptotic density $\left(N_{\infty}\right)$ was noted. This produced 'cumulative appearance curves' (CAC) similar in shape to growth curves. In addition, for every appearance of each worm on the Elsa video, the time spent out $\left(T_{0}\right)$ and the time spent in the tube between 2 successive appearances $\left(T_{\mathrm{i}}\right)$ were noted.

To obtain estimates of $N_{\infty}$, the CACs were modelled. The Richards function (Richards 1959) was chosen as a theoretical model because of its flexibility (it describes a wide family of curves). It can be written:

$$
N_{i}=N_{\infty}\left(1-b e^{-k t}\right)^{-n}
$$

where $N_{t}=$ number of individuals per $\mathrm{m}^{2}$ observed at time $t ; N_{\infty}=$ theoretical total density. $n$ is a shape parameter: when $n=-1$ the function is the von Bertalanffy equation, when $n=1$ the function is the logistic equation and as $|n|$ tends to $\infty$ the function approaches the Gompertz equation. $K$ is a constant; $b$ is a scaling parameter and can be written:

$$
b=\frac{N_{-1 / n}^{-1 / n} N_{0}^{-1 / n}}{N_{\infty}^{-1 / n}}
$$

where $N_{0}=$ theoretical $N_{i}$ value for $t=0$.

The parameters of the CAC equations were estimated by performing a non-linear regression (Venus \& Causton 1979, Ebert 1980, Schnute 1980). $N_{0}$ was estimated as the average $N_{1}$.

Biomass was either obtained from the actual alvinellid weights in the samples (to produce the sample biomass $B_{\mathrm{S}}$ ), or calculated from the video using $N_{\infty}$ and the mean weight of the worms visible on the screen. This fraction of the worms corresponded to a single size group (Jollivet unpubl.). Subsamples of alvinellids (30 individuals) of each species and at each site were 
measured, weighed wet, then crushed and dried for $24 \mathrm{~h}$ at $100^{\circ} \mathrm{C}$ in an oven, and weighed dry. Dried individuals were then reduced to ash in a muffle furnace at $480^{\circ} \mathrm{C}$ for $6 \mathrm{~h}$. The ash weight was used to calculate ash-free dry weights (AFDWs). Wet weight was only obtained from frozen animals, whereas AFDW also came from formalin-preserved specimens. The width of the seventh setigerous segment was used to characterize alvinellid size, because it is thought to be the most representative of biometrical characteristics in alvinellids (McHugh 1989). As correlation was very good between this size and AFDW values (Alvinella pompejana: $\mathrm{R}^{2}=0.96 ;$ A. caudata: $\mathrm{R}^{2}=0.93 ;$ Paralvinella grasslei: $\mathrm{R}^{2}=0.92 ;$ P pandorae irlandei: $\mathrm{R}^{2}=0.82$ ), we frequently used sizes to estimate AFDW.

\section{RESULTS}

\section{Ecological context}

The sequence at Elsa $\left(12^{\circ} 48.08^{\prime} \mathrm{N}, 103^{\circ} 56.34^{\prime} \mathrm{W}\right)$ included a young (stage $\mathrm{I}_{\text {; }}$ Haymon 1983) anhydrite white chimney $\left(1 \mathrm{~m}\right.$ high) diffusing $280^{\circ} \mathrm{C}$ fluid at the top. Fauna was almost exclusively composed of alvinellid polychaetes and Bythograea thermydron. Smallsized Riftia pachyptila were frequently observed in the periphery. At Parigo $\left(12^{\circ} 48.52^{\prime} \mathrm{N}, 103^{\circ} 56.48^{\prime} \mathrm{W}\right)$, the

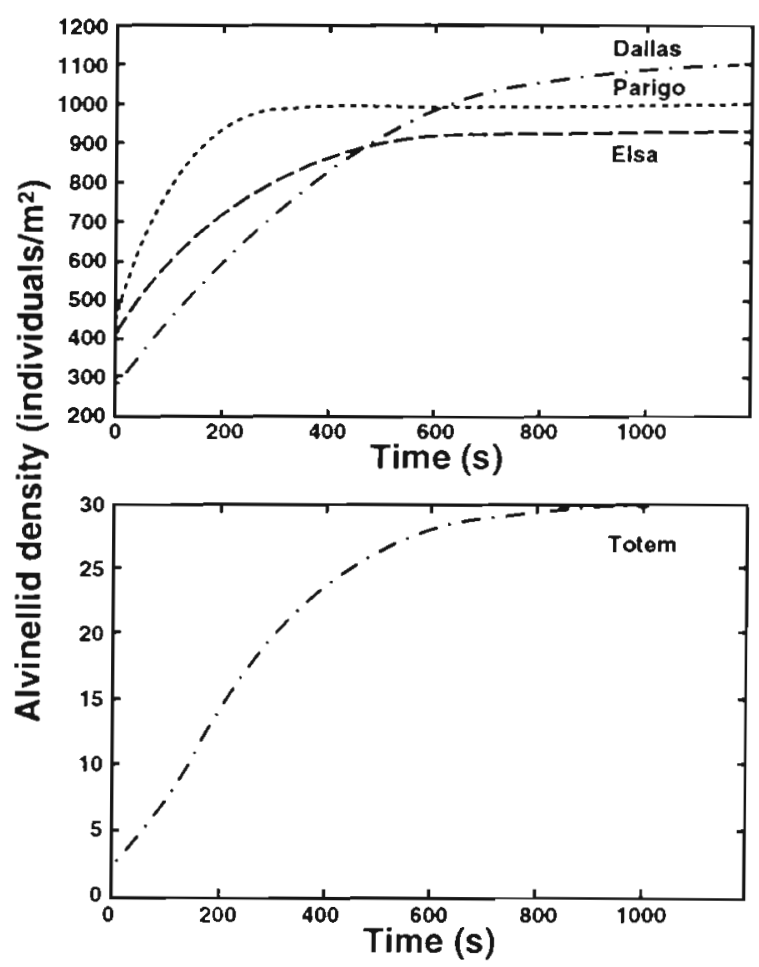

Fig. 2. Cumulative appearance curves (CACs) generated for 4 hydrothermal chimneys using the Richards equation observed chimney was an older (stage II) $2.5 \mathrm{~m}$ white smoker (see Fig. 5) with low temperature diffusion (5 to $18^{\circ} \mathrm{C}$ ), inhabited by numerous taxa such as peltospirid limpets, polychaetes (mainly Euphrosine rosacea and Hesiolyra bergi), small-sized $R$, pachyptila and numerous bythograeid crabs. At Totem $\left(12^{\circ} 48.72^{\prime} \mathrm{N}, 103^{\circ}\right.$ $56.53^{\prime} \mathrm{W}$ ), the chimney was a $2 \mathrm{~m}$ black smoker with very active fluid emission at the top. Black fluid temperature was $350^{\circ} \mathrm{C}$, whereas it was ca $20^{\circ} \mathrm{C}$ around the animals (large Alvinella spp., the peltospirid gastropod Melanodrymia aurantiaca and the crabs Cyanagraea praedator and $B$. thermydron). At Dallas $\left(12^{\circ} 48.11^{\prime} \mathrm{N}, 103^{\circ} 56.32^{\prime} \mathrm{W}\right)$, the chimney had 2 young (stage I) anhydrite black diffusers approximately $1 \mathrm{~m}$ high. Alvinellids were observed at the base of the chimney with numerous bythograeid crabs, peltospirid and lepetodrilid limpets and a few large $R$. pachyptila. Alvinellid samples were obtained from each site except Dallas. A qualitative assessment was made of each sample to determine its adequacy for quantitative studies. We found that the Elsa sample, unlike the others, was not a pure alvinellid sample but included a few $R$. pachyptila.

\section{Fitting the model}

Results from analysis of both the alvinellid samples and the video sequences are reported in Table 1 . The CACs look alike (Fig. 2); however for Parigo (the only stage II smoker), the curve reaches the asymptote more quickly. For Totem (the only black smoker) the $\mathrm{CAC}$ is very much flattened because of lower density. The Richards model fits the observed data very well, as indicated by the very high determination coefficients $\left(R^{2}\right)$. The shape parameters $n$ all indicate that CACs follow the Gompertz equation. White smokers all have similar $N_{\infty}$ (930 to 1115 ind. $\mathrm{m}^{-2}$ ), while the black smoker displays a much lower value of 30 ind. $\mathrm{m}^{-2}$. Densities obtained from sampling are higher than those obtained from the video but of the same magnitude. $N_{\infty}$ is lower because it does not account for small individuals beyond the resolution of the video. The Alvinella to Paralvinella ratio does not appear to be constant on white smokers, where both species occur. On the black smoker, Alvinella is the only genus sampled and observed. The shape of the CACs shows that, in general, most worms appeared at least once during the video recording.

\section{Biomass calculations}

Biomass $\left(B_{1}\right)$ was first estimated as a product of $N_{\infty}$ and the mean AFDW $(w)$ obtained from the sample:

$$
B_{1}=w N_{\infty}
$$


Table 1. Summary of data obtained from direct sampling and video from 4 hydrothermal chimneys. Stages I (young) and II (old) are arbitrarily defined smoker growth stages

\begin{tabular}{|c|c|c|c|c|c|}
\hline & $\begin{array}{l}\text { Site: } \\
\text { Smoker type: } \\
\text { Stage: }\end{array}$ & $\begin{array}{c}\text { Elsa } \\
\text { White } \\
I\end{array}$ & $\begin{array}{l}\text { Parigo } \\
\text { White } \\
\text { II }\end{array}$ & $\begin{array}{l}\text { Totem } \\
\text { Black } \\
\text { I }\end{array}$ & $\begin{array}{l}\text { Dallas } \\
\text { White } \\
\text { I }\end{array}$ \\
\hline \multicolumn{6}{|l|}{ Data from sampling } \\
\hline Number of alvinellids & & 295 & 260 & 90 & - \\
\hline Surface sampled $\left(\mathrm{m}^{2}\right)$ & & 0.190 & 0.190 & 0.875 & - \\
\hline$N$ : density (ind $\mathrm{m}^{-2}$ ) & & 1570 & 1370 & 105 & - \\
\hline \multicolumn{6}{|l|}{ Percentage of abundance } \\
\hline Alvinella pompejana & & 16.0 & 34.6 & 38.0 & - \\
\hline A. caudata & & - & 9.4 & 62.0 & - \\
\hline Paralvinella grasslei & & 78.0 & 56.0 & - & - \\
\hline P. pandorae irlandei & & 6.0 & - & - & - \\
\hline \multicolumn{6}{|l|}{ Percentage of biomass } \\
\hline A. pompejana & & 22.9 & 28.4 & 42.0 & - \\
\hline A. caudata & & - & 5.9 & 58.0 & - \\
\hline P. grasslei & & 77.0 & 65.7 & - & - \\
\hline P. p. irlandei & & 0.1 & - & - & - \\
\hline \multicolumn{6}{|l|}{ Mean AFDW $(g)$} \\
\hline A. pompejana & & 0.058 & 0.011 & 0.179 & - \\
\hline A. caudata & & - & 0.009 & 0.139 & - \\
\hline P. grasslei & & 0.038 & 0.015 & - & - \\
\hline P. p. irlandej & & 0.001 & - & - & - \\
\hline Total Alvinellidae & & 0.039 & 0.013 & 0.154 & $0.027^{\mathrm{a}}$ \\
\hline \multicolumn{6}{|l|}{ Data from video sequences } \\
\hline Surface studied $\left(\mathrm{m}^{2}\right)$ & & 0.130 & 0.085 & 0.585 & 0.045 \\
\hline \multicolumn{6}{|c|}{ Richards function parameter estimates } \\
\hline$N_{\infty}\left(\right.$ ind $\left.\mathrm{m}^{-2}\right) \pm \mathrm{SE}$ & & $930 \pm 27$ & $990 \pm 11$ & $30 \pm 2.5$ & $1115 \pm 12$ \\
\hline$b$ & & -0.012 & -0.007 & -0.047 & -0.054 \\
\hline$K$ & & 0.006 & 0.042 & 0.003 & 0.004 \\
\hline$n$ & & 71 & 127 & 57 & 27 \\
\hline $\mathrm{R}^{2}$ (determination coefficient) & & 0.97 & 0.97 & 0.98 & 0.99 \\
\hline$N_{0} / N_{\infty}$ & & 0.438 & 0.412 & 0.072 & 0.242 \\
\hline \multicolumn{6}{|c|}{ Visible/non-visible worms biomass ratio } \\
\hline$p$ & & 0.09 & 0.03 & 0.36 & $0.06^{\mathrm{d}}$ \\
\hline \multicolumn{6}{|l|}{ Mean AFDW of the visible fraction } \\
\hline Total Alvinellidae & & 0.063 & 0.017 & 0.395 & $0.041^{b}$ \\
\hline
\end{tabular}

Results are reported in Table 2, together with the biomasses calculated from the samples' densities $\left(B_{S}\right)$. When compared with $B_{\mathrm{S}}, B_{1}$ is much lower, sometimes by a factor of 2 to 3 . This again is not surprising, because $N_{\infty}$ only refers to the worms visible on the video, and is lower than the actual density. Also, $w$ is the mean weight of alvinellids belonging to several size groups. By comparing $N_{\infty}$ with sampling densities $(N)$, it was possible to estimate the size critical for observation on size frequency histograms: mean weights were then calculated for both groups of worms, below and above critical size. This gave us the biomass proportion $p$ of the small non-visible worms. Therefore, we produced a second biomass value, $B_{\vee}$ (visible biomass), calculated as follows:

$$
B_{\vee}=w_{\vee} N_{\infty}
$$

where $w_{V}=$ mean AFDW of the worms visible on the video. $B_{\vee}$ values are very close to $B_{\mathrm{S}}$ (Table 2 ), except for Totem (because the distance of observation was greater). However, all 4 values are lower than $B_{\mathrm{S}}$, because the non-visible fraction of the worms was not taken into account. To account for that correction, total biomass $\left(B_{2}\right)$ can be calculated as: 
Table 2. Biomass ( $\mathrm{g}$ AFDW $\mathrm{m}^{-2}$ ) of alvinellid assemblages, estimated according to different methods. See text for explanations

\begin{tabular}{|c|c|c|c|c|}
\hline & \multicolumn{4}{|c|}{ Site } \\
\hline & Elsa & Parigo & Totem & Dallas \\
\hline$B_{\mathrm{S}}$ & 60.5 & 17.9 & 16.0 & - \\
\hline$B_{1}$ & 36.3 & 12.9 & 4.6 & 30.1 \\
\hline$B_{V}$ & 58.6 & 16.8 & 11.9 & 45.7 \\
\hline$B_{2}$ & 63.9 & 17.3 & 16.1 & 48.5 \\
\hline
\end{tabular}

Thus,

$$
B_{2}=B_{V}+B_{\mathrm{NV}} \text { and } p=B_{\mathrm{NV}} / B_{V}
$$

$B_{2}=B_{V}+p B_{V}$

yielding

$$
B_{2}=B_{\vee}(1+p)
$$

$$
B_{2}=w_{V} N_{c o}(1+p)
$$

$B_{\mathrm{NV}}=$ biomass of non-visible worms. $B_{2}$ values are in good agreement with $B_{\varsigma}$ values (Table 2), which was expected, as a direct relationship exists between $p$ and $B_{\mathrm{S}}: p$ is close to $\left(B_{\mathrm{S}}-B_{\mathrm{V}}\right) / B_{\vee}$. Again, the biomass proportion $p$ of non-visible alvinellids for Totem is much higher than for the others because the submersible-tochimney distance was twice as great. It appears that $p$ was an important correction factor in that particular case. Mean AFDWs appear to differ between sites: in the present study, both species of Alvinella were significantly smaller on white smokers than on black smokers. Parigo was characterized by very small Alvinella. Dallas seemed to be intermediate between the 2 other white chimneys. Parigo, because of its small-sized alvinellids, had the lowest biomass for a white smoker, while Totem displayed the lowest biomass of all smokers. Water constituted about $90 \%$ of the wet weight of Alvinella spp. and $80 \%$ of Paralvinella grasslei, which allows estimates of wet weight biomass from our AFDW values, for comparison with literature values. Observed wet biomasses range from 140 (Parigo) to $520 \mathrm{~g} \mathrm{~m}^{-2}$ (ELSA).

\section{Alvinellid behaviour}

The marked difference in the CAC of Totem was thought to be due to the $100 \%$ Alvinella spp. proportion, and the flattening of the curve to a difference in behaviour between the 2 genera (Alvinella and Paralvinella). In cases where both occurred, as at Elsa, resolution on the video was good enough to identify large Alvinella spp. on screen, which seemed to come out of their tubes much less frequently and for a much shorter time than most of the remaining small visible worms.
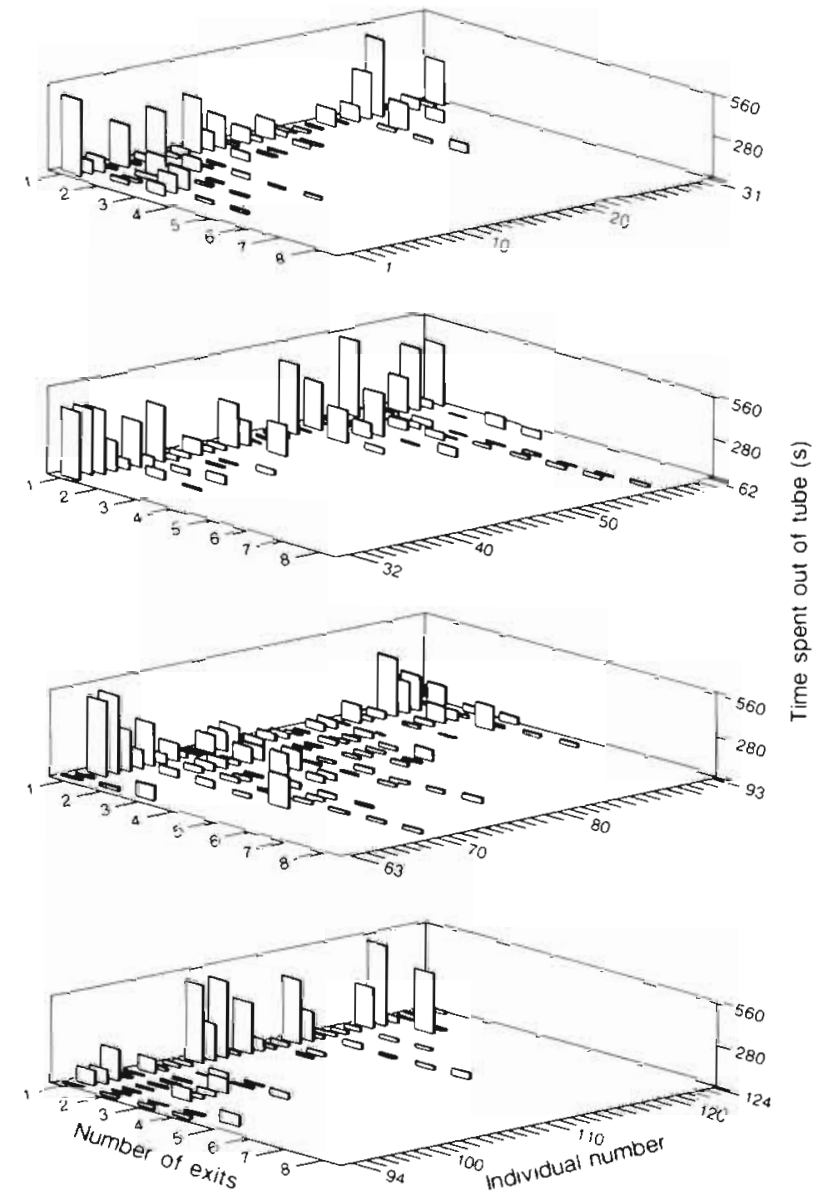

Fig. 3. Three-dimensional histograms showing the individual behavioural pattern of each worm, on the video sequence at Elsa hydrothermal site

Behaviour is not suspected to have been influenced by mobile megafauna (e.g. crabs): only 0 to 2 Bythograea thermydron entered the camera's field of view (small areas, see Table 1) at each site as crab densities were not important and duration of video recording relatively short with regard to crab movements. Fig. 3 clearly shows that alvinellids display various behavioural patterns. The average $T_{0}$ and $T_{\mathrm{i}}$ for each individual were then reported on another 3-dimensional frequency histogram (Fig. 4) showing 3 behavioural clusters: Cluster 1 was characterized by a low $T_{0}$ and a high $T_{i}$ and is clearly identified as belonging to the Alvinella genus. Cluster 2 had a high $T_{0}$ and a low $T_{1}$ and is thought to represent Paralvinella grasslei. Cluster 3 , with a low $T_{0}$ and $T_{i}$, may represent a second $P$. grasslei group with a different behavioural pattern, or a mixture of both genera. When grouping Clusters 2 and 3 for each of the 4 sites, the percentages of abundance in Table 3 (Totem has 100\% Alvinella spp.) match those from the samples (Table 1), except for the ELSA data which, nevertheless do not discount this 


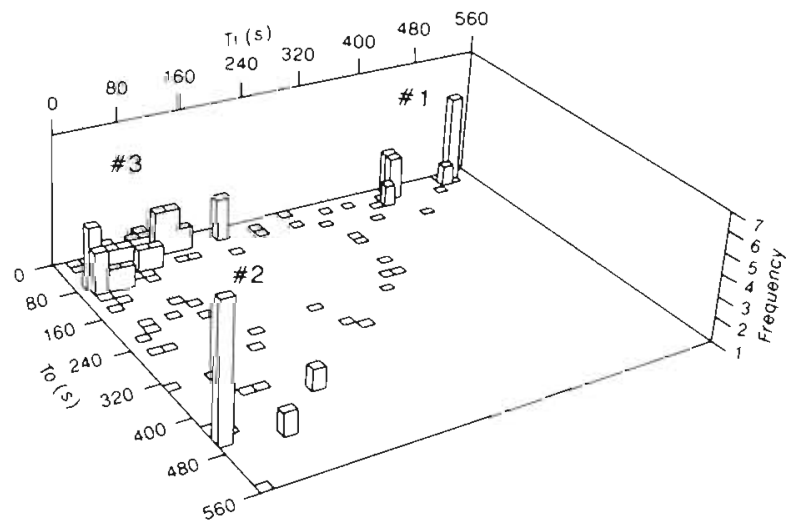

Fig. 4. Three-dimensional frequency histogram of the time spent in $\left(T_{1}\right)$ and the time spent out of the tube $\left(T_{0}\right)$ for Alvinellidae visible on the video sequence at Elsa hydrothermal site. \#1, \#2 and \#3 represent behavioural clusters described in the text

grouping. We thus assumed that Cluster 3 corresponded to $P$. grasslei.

In order to take into account this behavioural heterogeneity in multispecific alvinellid assemblages, the model was then applied separately to the genera Alvinella and Paralvinella (Table 3). $p$ was expected to be higher for Paralvinella than for Alvinella, but this was not the case for Parigo, where $A$. pompejana and A. caudata were about the size of $P$. grasslej. Biomass values are slightly different from those of the general model, but in the same range.

\section{Theoretical upper limit for alvinellid biomass}

Model simulations estimated maximum alvinellid biomass. This value, $B_{\max }$ was defined as follows:

$$
\begin{aligned}
B_{\max } & =B_{\mathrm{A} \max }+B_{\mathrm{P} \max } \\
& =\left(1+p_{\max }\right)\left[\left(w_{A_{\max }} N_{A_{\infty} \max }\right)+\left(w_{\mathrm{P} \max } N_{\mathrm{P}_{\infty} \max }\right)\right]
\end{aligned}
$$

where $B_{\mathrm{A} \max }$ and $B_{\mathrm{P} \max }=$ theoretical maximum biomasses for Alvinella and Paralvinella, respectively; $p_{\max }=$ maximal value for $p$ on a given type of smoker; $w_{A \max }(1.51 \mathrm{~g})$ and $w_{\mathrm{p} \max }(0.166 \mathrm{~g})=$ highest individual AFDW values available to us (in alvinellid collections from $13^{\circ} \mathrm{N} / \mathrm{EPR}$ ) for the 2 genera. For black smokers, $B_{\mathrm{P}} \max$ tends towards 0 , the density is that of Totem

\begin{tabular}{|c|c|c|c|}
\hline & Elsa & $\begin{array}{c}\text { Site } \\
\text { Parigo }\end{array}$ & Dallas \\
\hline \multicolumn{4}{|c|}{ Abundance \% determined from behaviour } \\
\hline Alvinella spp. & 36.6 & 40.7 & 41.0 \\
\hline Paralvinella spp. & 63.4 & 59.3 & 59.0 \\
\hline \multicolumn{4}{|l|}{ Visible/non-visible biomass ratio } \\
\hline$p$ for Alvinella spp. & 0.030 & 0.029 & $0.030^{\mathrm{a}}$ \\
\hline$p$ for Paralvinella spp. & 0.120 & 0.027 & $0.074^{\mathrm{d}}$ \\
\hline \multicolumn{4}{|l|}{ Mean AFDW $(g)$ - visible fraction } \\
\hline Alvinella spp. & 0.075 & 0.016 & $0.033^{b}$ \\
\hline Paralvinella spp. & 0.061 & 0.018 & $0.045^{\mathrm{h}}$ \\
\hline \multicolumn{4}{|c|}{ Richards parameter estimates for Alvinella spp. } \\
\hline$N_{\infty}\left(\right.$ ind. $\left.\mathrm{m}^{-2}\right)$ & 380 & 400 & 490 \\
\hline$b$ & -0.022 & -0.020 & -0.029 \\
\hline$K$ & 0.004 & 0.035 & 0.004 \\
\hline$n$ & 74 & 87 & 98 \\
\hline $\mathrm{R}^{2}$ (determination coefficient) & 0.97 & 0.97 & 0.98 \\
\hline \multicolumn{4}{|c|}{ Richards parameter estimates for Paralvinella spp. } \\
\hline$N_{\infty}\left(\right.$ ind $\left.\mathrm{m}^{-2}\right)$ & 585 & 595 & 605 \\
\hline$b$ & -0.008 & -0.006 & -0.023 \\
\hline$K$ & 0.009 & 0.084 & 0.007 \\
\hline$n$ & 75 & 86 & 45 \\
\hline $\mathrm{R}^{2}$ (determination coefficient) & 0.98 & 0.98 & 0.97 \\
\hline \multicolumn{4}{|l|}{ Biomass (g AFDW $\mathrm{m}^{-2}$ ) } \\
\hline$B_{A}($ Alvinella spp. biomass $)$ & 29.6 & 7.0 & 17.2 \\
\hline$B_{\mathrm{p}}$ (Paralvinella spp biomass) & 40.5 & 11.6 & 29.7 \\
\hline$B_{A}+B_{P}$ & 70.1 & 18.6 & 46.9 \\
\hline
\end{tabular}

Table 3. Summary of the data obtained when separatıng Alvinella spp. from Paralvinella spp. for biomass calculations 
(30 ind $\mathrm{m}^{-2}$ ), and $p=0.36$, which produces a biomass value of $62 \mathrm{~g} \mathrm{AFDW} \mathrm{m}{ }^{-2}$ ( $\mathrm{ca} 650 \mathrm{~g}$ wet wt $\mathrm{m}^{-2}$ ). On white smokers, $N_{A_{\infty} \max }$ (490) and $N_{P_{\infty}} \max (605)$ are chosen as the highest values for this parameter in Table 3 , and the highest $p$ for white smokers is 0.09 . According to this calculation, the theoretical maximum biomass for alvinellids on a white smoker would be $916 \mathrm{~g} \mathrm{AFDW} \mathrm{m^{-2 }}<<10 \mathrm{~kg}$ wet wt $\mathrm{m}^{-2}$ ).

\section{Spatial variability of alvinellid biomass}

Biomass estimates were made on a whole smoker at Parigo because of the availability of good video coverage. Preliminary observations indicated considerable heterogeneity in alvinellid distribution and density. The structure was first modelled by simple geometric forms (Fig. 5) from which total surface area was estimated to be $13 \mathrm{~m}^{2}$. Alvinellid tubes covered approximately $41.5 \%$ of that surface. Since the video sequences did not last long enough to evaluate $N_{\infty}$ on each part of the smoker, only $N_{0}$ was noted. It was assumed that the ratio $N_{0} / N_{\infty}$ i. e. the proportion of individuals out at a given time, would be fairly constant at least on the same chimney. This ratio was 0.412 for Parigo and allowed $N_{\infty}$ estimates for the main 3
Table 4. Characteristics of alvinellid populations at 3 levels of the Parigo white smoker

\begin{tabular}{|c|c|c|c|}
\hline Level & A. pompejana & A. Caudata & P. grasslei \\
\hline Top & \multicolumn{3}{|c|}{$\begin{array}{c}\text { Density: } 770 \text { to } 840 \text { ind } \mathrm{m}^{-2}(\mathrm{n}=2) \\
\text { Biomass (AFDW): } 30.5 \mathrm{~g} \mathrm{~m}^{-2}\end{array}$} \\
\hline Proportion (\%) & 44.2 & 18.4 & 37.4 \\
\hline Mean size $(\mathrm{mm})$ & $2.71 \pm 0.24$ & $3.31 \pm 0.24$ & $2.17 \pm 0.12$ \\
\hline Mean AFDW - visible $(g)$ & 0.037 & 0.075 & 0.018 \\
\hline Middle & \multicolumn{3}{|c|}{$\begin{array}{l}\text { Density: } 430 \text { to } 465 \text { ind. } \mathrm{m}^{-2}(\mathrm{n}=2) \\
\text { Biomass (AFDW): } 10.7 \mathrm{~g} \mathrm{~m}^{-2}\end{array}$} \\
\hline Proportion (\%) & 35.4 & 20.0 & 44.6 \\
\hline Mean size $(\mathrm{mm})$ & $2.67 \pm 0.16$ & $2.11 \pm 0.21$ & $2.15 \pm 0.12$ \\
\hline Mean AFDW - visible $(g)$ & 0.033 & 0.018 & 0.018 \\
\hline Base & \multicolumn{3}{|c|}{$\begin{array}{l}\text { Density: } 1310 \text { to } 1540 \text { ind. } \mathrm{m}^{-2}(\mathrm{n}=3) \\
\text { Biomass (AFDW): } 26.0 \mathrm{~g} \mathrm{~m}^{-2}\end{array}$} \\
\hline Proportion (\%) & 34.6 & 9.4 & 56.0 \\
\hline Mean size (mm) & $2.11 \pm 0.1$ & $2.04 \pm 0.4$ & $2.22 \pm 0.07$ \\
\hline Mean AFDW - visible $(g)$ & 0.018 & 0.018 & 0.018 \\
\hline
\end{tabular}

chimney units: top, middle and base. Results are presented in Table 4 . Density was maximum at the base and minimum in the middle, but while biomass was also minimum in the middle, it was maximum at the base and the top of the chimney. This was due to the predominance of Paralvinella grasslei at the base, which were more numerous but smaller than the Alvinella species that dominate the top. Also, Alvinella

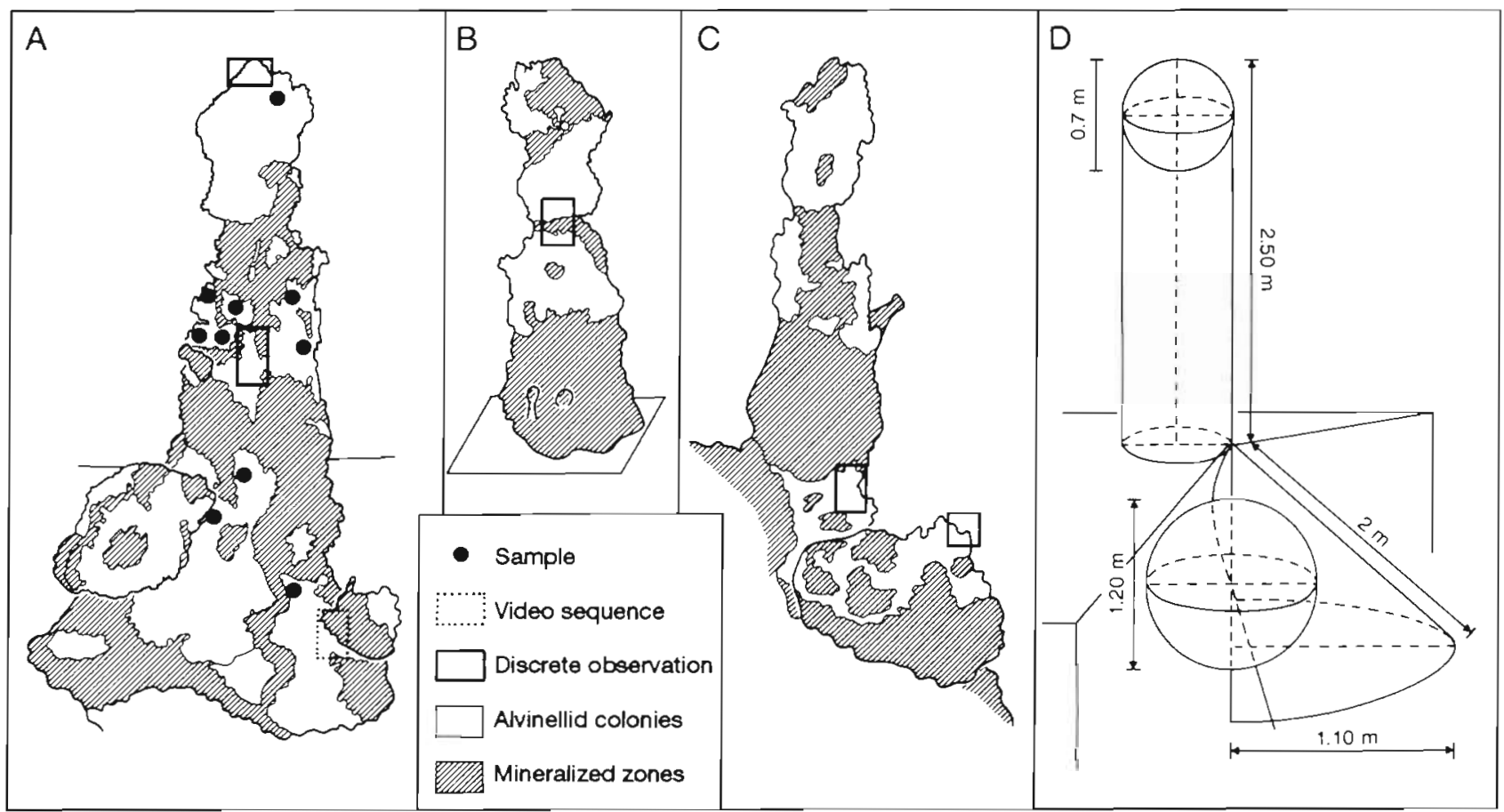

Fig. 5. Schematic representation of the Parigo chimney. (A) Southwest side; (B) southeast side; (C) north side; (D) geometrical model of the chimney surface 
spp.' mean size and weight decrease from top to base, whereas they are almost constant in $P$. grasslei [all Mann-Whitney tests show a significant difference (at least $\mathrm{p}<0.05$ ) for Alvinella spp., while they do not for $P$. grasslei]. The mean biomass for the whole smoker was $22.4 \mathrm{~g} \mathrm{AFDW} \mathrm{m}^{-2}$, which is consistent with the value obtained for Parigo in Table 2 . We can estimate the Parigo smoker to represent a total AFDW alvinellid biomass of $120 \mathrm{~g}$ (approximately $1 \mathrm{~kg}$ wet $\mathrm{wt}$ ).

\section{DISCUSSION}

We can reliably estimate alvinellid biomass in a range of environmental conditions with novel methods of estimating surface area and alvinellid densities. Alvinellid behaviour is the key to obtaining these densities

\section{Limitations and future prospects of the biomass estimation method}

\section{Surface estimation}

The limitations of our surface-estimation method depend on the error made when assuming the size of the scaling object: i.e. we used crabs for scaling, whose size was assumed to be the modal length of the adult crabs' size group. However, knowing these limitations, the method seems to be very accurate when no distance-measuring system is available. The values obtained for the angle of incidence $\theta$ are not biased: they do not depend on the scaling animal's size but on its isometry ratio. As measuring devices will probably be developed in the future, it seems appropriate to stress the ideal system. A centred laser beam would give an accurate estimate of the distance $D$. Estimating $\theta$, if not determined using our technique, would require 4 additional parallel beams creating orthogonal axes (Davis \& Tusting 1991) or a single beam successively recording the distance of these 4 points.

\section{Using the Richards model to approach biomass}

This is, to our knowledge, the first time the Richards model has been applied outside of growth studies, but it has proved to be efficient and very convenient for our application. The ultimate goal would be to obtain biomass values calculated independently from the sampling surface. This method is particularly adapted to fields where imagery and samples are available but where a quadrat-like sampling technique is impossible, such as in a hydrothermal environment. Any kind of tube-dwelling or burrowing megafaunal animal can be studied in this way. The density of visible worms $\left(N_{\omega}\right)$ can now easily be obtained with our method from any good-quality video, but calculations still require from the field the mean weight of the visible fraction $\left(w_{V}\right)$, and the correction factor $p$, which are tied to each other

While surface estimates are not required in order to obtain mean alvinellid weights from a sample, a problem still remains with the correction factor $p$ and $w_{v}$. In the present study, we had to obtain a good estimate of the surface sampled by the submersible's arm in order to deduce a $B_{\mathrm{S}}$ value (used for $p$ calculations) and validate the method. $p$ depends on 2 possible factors: the first is the distance to the chimney, which is clear when comparing Elsa, Parigo and Dallas to the Totem video taken from a greater distance, where a lot of small animals could not be seen on the screen. The second factor is more theoretical: as differences occurred in $p$ values of videos taken from approximately the same distance (on white smokers, $p$ varied from 0.03 to 0.09 ), variations in the population structure may also influence $p$, except if these variations were induced by inaccuracies in the $D$ estimates. Sampling is necessary to determine the percentage of non-visible worms. If $p$ is calculated as a biomass ratio (as in the present work), there will still be a requirement for an estimate of the surface sampled. However, solutions exist to circumvent this problem. Assuming behaviour does not change with individual size, a size-limit may be set artificially that would be higher than the one imposed by the video resolution. By setting this limit, $p$ could then be calculated from any sample as the ratio between the total weight of the individuals below and above this critical size, without referring to a surface. Confidence becomes greater as the counts on the video screen are more accurate, and may further be aided by imageprocessing tools.

The $N_{0} / N_{\infty}$ ratio, or proportion of worms out at a given time, might be an interesting parameter in the future. This ratio may be used to estimate $N_{\infty}$ from photographs or from short videos. Although we have too few data to make precise statements, it can be related to smoker type and to the proportion of each genus. It is rather similar for the 3 white smokers (mean $0.36 \pm$ 0.11 ).

In addition, it seems important to separate Alvinella from Paralvinella when estimating biomass. Our results did not show great differences in the mean AFDW of the 2 genera, but as Alvinella spp. can sometimes be considerably bigger than Paralvinella spp., it is clear the two should be separated. Mean weight values could also be obtained from the literature, but they seem to be too variable to produce reliable biomass estimates. The proportion of each genus in the assem- 
blage can be determined by looking at the general behaviour, and can therefore be estimated without sampling.

\section{Biomass values}

Alvinellid biomasses calculated in the present study were much lower than the values from the literature, although it is often difficult to compare results from different authors and methods. Our values range from approximately 15 to $65 \mathrm{~g} \mathrm{AFDW} \mathrm{m}^{-2}$ (about 150 to $500 \mathrm{~g}$ wet wt $\mathrm{m}^{-2}$ ), and we hypothesized, from simulations with maximal densities and weights, that it was unlikely ever to reach $900 \mathrm{~g} \mathrm{AFDW} \mathrm{m}^{-2}$ (about $9 \mathrm{~kg}$ wet wt $\mathrm{m}^{-2}$ ) on any given surface. Brault et al. (1985) reported a wet weight value of $16 \mathrm{~kg} \mathrm{~m}^{-2}$ for alvinellids, including tubes. Assuming the alvinellid-to-tube ratio found by Fustec et al. (1988) is correct and constant (animals = one-third of the total weight), which is very unlikely, the $16 \mathrm{~kg} \mathrm{~m}^{-2}$ value would produce a wet weight biomass of alvinellids without tubes close to $5 \mathrm{~kg} \mathrm{~m}^{-2}$, which we consider unrealistic.

The results of Fustec et al. (1988) are much more detailed, and allow better comparisons and comments. These authors deduced biomass from population density by assigning to each individual the average weight measured from a small sample set. While they could easily estimate Riftia pachyptila densities by counting plumes or tubes on photographs or videos, their alvinellid values come from a single grab sample, divided by the area covered by the arm's claw: $50 \mathrm{~g}$ of worms and $100 \mathrm{~g}$ of tubes for $0.02 \mathrm{~m}^{2}$, i. e. biomasses of $2.5 \mathrm{~kg}$ $\mathrm{m}^{-2}$ without tubes and $7.5 \mathrm{~kg} \mathrm{~m}^{-2}$ including tubes (wet $w t)$. They extrapolated this value to a whole chimney, producing the figure of $220 \mathrm{~kg}$ wet wt for $35 \mathrm{~m}^{2}(6.3 \mathrm{~kg}$ $\mathrm{m}^{-2}$ ). These data also exceed the maximal value we have calculated by a factor of 5 . Though we cannot discount the influence of spatial variability in alvinellid populations in explaining this difference, the very small size of the surface sampled with the arm of the submersible 'Cyana' $\left(0.02 \mathrm{~m}^{2}\right)$ could have produced such a discrepancy. These estimates could be poorly representative of the whole chimney $\left(35 \mathrm{~m}^{2}\right)$, considering the patchiness of alvinellid distribution. Also, the alvinellid assemblage at the collection site, Actinoir, represented a particular case, with numerous large Alvinella individuals and very few Paralvinella grasslei. Sampling of only 1 type of assemblage must be considered as such. Our samples however are restricted to 2 types of alvinellid assemblages: one with high densities of small animals (Elsa, Parigo, Dallas), and one with low densities of large animals (Totem). We have more recently observed another type with apparently high densities and large animals (primarily $A$. pompejana). Detailed data are as yet not available, but this was the case on very active smokers at the Genesis and Totem hydrothermal sites (EPR/13 ${ }^{\circ} \mathrm{N}$ ) in 1990 , where biomass may therefore be higher than in our present results, and could reach 1 to $2 \mathrm{~kg}$ wet wt $\mathrm{m}^{-2}$ (Jollivet unpubl.).

In previous studies, tubes have been taken into account for biomass calculations. We believe it might be an important source of error: alvinellid tubes form a 3 dimensional matrix in which the worms presumably live in the top few $\mathrm{cm}$ : if the worms are considered for biomass calculations excluding their tubes, sampling a surface will give a very close estimation of worms' biomass. If tubes are to be counted, then the whole volume of tubes from the surface to the chimney wall, should have been sampled with a corer-like instrument, and not with the claw of the 'Cyana'. Although tubes are an integral part of the worms' production, a bias is introduced when taking them into account, as an undefined but non-negligible part is uninhabited. Furthermore, only AFDW values would be significant as recent studies show that the tubes' organic content is only 15 to $30 \%$ (A. Khripounoff pers. com.).

\section{Alvinellid behaviour}

The behavioural patterns of alvinellids are probably influenced by differences in their physiological requirements. Tunnicliffe et al. (1990) suggested emergence/retraction movements of Vestimentifera are governed by oxygen requirements, and Chevaldonné et al. (1991) proposed that such movements in alvinellids may also be thermoregulatory behaviour. As 3 distinct behavioural patterns were observed, we may hypothesize the existence of 3 separate ecological requirements. These patterns are not species-specific. Although Desbruyères \& Laubier (1986) suggested sympatry could occur between Alvinella pompejana and A. caudata because of different ecological requirements, we did not find a corresponding difference in their behaviour. Conversely, 2 different behaviour patterns seem to exist for Paralvinella grasslei, which we cannot explain. Apart from the different ecological requirements, the origin of the behavioural differentiation between the 2 genera may be due to the difference in tube structure. Having a well-organized tube (as opposed to mucus secretions), Alvinella spp. may be more protected from environmental variability, similar to the bivalves which are protected by their shell (Chevaldonné et al. 1991). This characteristic may enable this genus to settle in niches more extreme than $P$. grasslei. Because Alvinella spp. have evolved under harsher conditions, their behaviour can be expected to be more closely related to the tubes. Conversely, the more opportunistic $P$. grasslei is able to survive in 
much 'colder' environments such as vestimentiferan clumps. Alvinella spp behaviour may also depend on the presence of dense populations of epibacteria on its body. The nature of this association is not yet understood (Alayse-Danet et al. 1987), but the epibionts may be favoured when in the tube, which may stimulate the worm to remain sedentary. We also noted that Alvinella spp. sometimes entered nearby tube openings, head forward, for a few seconds. This behaviour was also reported by Fustec et al. (1987), who suggested that the worms frequently changed tubes. We are inclined to reject this hypothesis because Alvinella spp. have never been seen entirely changing tubes under normal conditions, and because Herpin (1925) described this behaviour as a characteristic of mating activity in some Terebellomorpha.

\section{Spatial variability of alvinellid assemblages}

Biomass, species composition and biometrical parameters are highly variable from chimney to chimney. This is probably a result of variations both in the environmental conditions and in the recruitment patterns of alvinellid species. Spatial and temporal effects are always very intricate in the hydrothermal environment. Spatial variability observed on a single chimney at Parigo reflects differences in the microhabitat and in the settling strategies of the 2 genera. Density and biomass are minimal in the middle part of the chimney, probably due to environmental characteristics. At $13^{\circ} \mathrm{N} / \mathrm{EPR}$ sites, fluid diffusion is most often greatest at the top of chimneys and least in the mineralizing middle part, where Riftia pachyptila sometimes settles (Fustec et al. 1987). Alvinella spp. and Paralvinella grasslei are in equal proportions throughout the chimney except in the upper part, where increasing diffusion favours Alvinella spp. Another feature of alvinellid spatial distribution is that the $P$. grasslei population is almost homogeneous in size throughout the smoker, while Alvinella spp. are much larger in the upper portions. This was confirmed by size-frequency histograms (Jollivet unpubl.): assuming size (width of the seventh setigerous segment) is related to age in alvinellids, the $A$. pompejana population on the Parigo smoker is made of 3 size groups. The youngest is dominant at the base, the oldest on the top, and the medium one is mostly represented in the middle part. On the same smoker, the $P$. grasslei population consists mostly of 2 size groups. While only the older one is represented in the upper part of the smoker, both size groups are in almost equal proportions elsewhere Furthermore, S. C. Cary (pers. com.) noted that alvinellids eggs are negatively buoyant, favouring early development at the base of the chimneys. P. grasslei, which appeared to have a greater ability to move on the surface of the chimneys, and does not build structured tubes, may partially homogenize its population structure throughout the whole smoker. Conversely, we might expect the more sedentary Alvinella spp. individuals to be older on top than at the base of the chimneys. As the smokers accrete from the top, Alvinella spp. seem gradually to construct their tubes upward, along the chimney wall, possibly in an effort to maintain optimal environmental conditions. They do not build U-shaped tubes, as mentioned in the literature (Desbruyères et al. 1985). This was typically observed on very young chimneys, where A. pompejana tubes grew directly on the chimney sulphides. While abundant at the base, they had not yet settled on the upper third, although thermal conditions were similar (unpubl. results). This behaviour has already been described for Paralvinella sulfincola in the Northeast Pacific vents, which has many similarities with Alvinella species (Tunnicliffe \& Juniper 1990, Juniper et al. 1992, Tunnicliffe et al. 1993).

Alvinellids still remain the least-understood of Eastern Pacific hydrothermal taxa, because alvinellid research needs new techniques to circumvent the sampling problems. The uniqueness of alvinellids lies in their associated microorganisms, their influence on hydrothermal chimney formation, but most of all, in their peculiar adaptations to extreme environmental conditions: high temperatures, low oxygen tensions if not anoxy, tremendous temporal variability and substrate instability.

Acknowledgements. We thank the captain and crew of NO 'Nadir', the DSRV 'Nautile' crew and the SAE team who allowed us to perform 'Nautile' experiments in the Toulon seawater tank. We thank Anne-Marie Alayse, chief scientist on the HYDRONAUT cruise, and Daniel Desbruyeres for constant support, advice and helpful criticism. We also thank Philippe Gros who introduced us to the Richards model, Georges Barbier and Michel Le Haitre for discussions on surface calculations. We are also indebted to Violaine Martin for illustrations and Craig Cary, André Toulmond, Lucien Laubier and Jim Childress for critical review of the manuscript. This work was supported by IFREMER (research cruise and grants).

\section{LITERATURE CITED}

Alayse-Danet, A. M., Desbruyères, D., Gaill, F. (1987). The possible nutritional or detoxification role of the epibiotic bacteria of Alvinellid polychaetes: review of current data. Symbiosis 4: 51-62

Bourgoin, A., Guillou, M., Morvan, C. (1985). Etude préliminaire de l'épifaune des sédiments meubles de la rade de Brest (Finistère, France) à l'aide d'une caméra vidéo sous-marine. Annls Inst. Océanogr., Paris 61: 39-50

Brault, M., Marty, J.-C., Saliot, A., Laubier, L. (1985). Traceurs biogéochimiques (hydrocarbures et acides gras) dans 
l'eau de mer environnant un peuplement hydrothermal de la ride Est-Pacifique à $13^{\circ}$ N. C. r. hebd. Séanc. Acad. Sci., Paris 301: 1-8

Chevaldonné, P., Desbruyères, D., Le Haitre, M. (1991). Timeseries of temperature from three deep-sea hydrothermal vent sites. Deep Sea Res. 38: 1417-1430

Corliss, J. B., Dymond, J., Gordon, L. I., Edmond, J. M., Von Herzen, R. P., Ballard, R. D., Green, K. Williams, D., Bainbridge, A., Crane, K., van Andel, T. H. (1979). Submarine thermal springs on the Galapagos Rift. Science 203: $1073-1083$

Davis, D. L., Tusting, R. F. (1991). Quantitative benthic photography using laser calibrations. Proceedings of Undersea World 91, San Diego, April 16-18, 1991. West Star Productions, San Diego, p. 39-43

Desbruyères, D., Gaill, F., Laubier, L., Fouquet, Y (1985) Polychaetous annelids from hydrothermal vent ecosystems: an ecological overview. Bull. biol. Soc. Wash. 6: $103-116$

Desbruyères, D., Laubier, L. (1980). Alvinella pompejana gen. sp. nov., Ampharetidae aberrant des sources hydrothermales de la ride Est-Pacifique. Oceanol. Acta 3: $267-274$

Desbruyères, D., Laubier, L. (1982). Paralvinella grasslei, new genus, new species of Alvinellinae (Polychaeta: Amphare. tidae) from the Galapagos Rift geothermal vents. Proc. biol. Soc. Wash. 95: 484-494

Desbruyères, D., Laubier, L. (1986). Les Alvinellidae, une famille nouvelle d'annélides polychètes inféodées aux sources hydrothermales sous-marines: systématique, biologie et écologie. Can. J. Zool. 64: 2227-2245

Desbruyères, D., Laubier, L. (1991). Systematics, phylogeny, ecology and distribution of the Alvinellidae (Polychaeta) from deep-sea hydrothermal vents. Ophelia Suppl. 5: $31-45$

Ebert, T. A. (1980). Estimating parameters in a flexible growth equation, the Richards function. Can. J. Fish. Aquat. Sci. 37: $687-692$

Fustec, A., Desbruyères, D., Juniper, S. K. (1987). Deep-sea hydrothermal vents community at $13^{\circ} \mathrm{N}$ on the east Pacific rise: microdistribution and temporal variations. Biol. Oceanogr. $4: 121-164$

Fustec, A., Desbruyères, D., Laubier, L. (1988). Estimation de la biomasse des peuplements associés aux sources hydrothermales profondes de la dorsale du Pacifique oriental à $13^{\circ} \mathrm{N}$. Oceanol. Acta SP8: $15-21$

Haymon, R. M. (1983). Growth history of hydrothermal black smoker chimneys. Nature 301: 695-698

Herpin, R. (1925). La ponte et le développement chez une annélide polychète sédentaire Nicolea zostericola. C. r hebd. Séanc. Acad. Sci, Paris 180: 864-866

Hessler, R. R. Smithey, W. M. Jr (1983). The distribution and community structure of megafauna at the Galapagos Rift hydrothermal vents. In: Rona, P. A., Bostrom, K., Laubier,
L., Smith, K. L. Jr (eds.) Hydrothermal processes at seafloor spreading centers. Plenum Press, New York, p. $735-770$

Juniper, S. K., Jonasson, I. R., Tunnicliffe, V., Southward, A. J. (1992). Influence of a tube-building polychaete on hydrothermal chimney mineralization. Geology 20: 895-898

Laubier, L. (1989). Ecosystèmes benthiques profonds et chimiosynthèse bactérienne: sources hydrothermales et suintements froids. In: Denis, M. (ed.) Océanologie, actualités et prospective. Centre d'Océanologie de Marseille Publications, Marseille, p. 61-96

Lonsdale, P. (1977). Clustering of suspension-feeding macrobenthos near abyssal hydrothermal vents at oceanic spreading centers. Deep Sea Res. 24: 857-863

McHugh, D. (1989). Population structure and reproductive biology of two sympatric hydrothermal vent polychaetes, Paralvinella pandorae and P. palmiformis. Mar. Biol. 103: 95-106

Rice, A. L., Collins, E. P. (1985). The use of photography in deep-sea benthic biology at the Institute of Oceanographic Sciences. In: George, J. D., Lythgoe, G. I., Lythgoe, J. N. (eds.) Underwater photography and television for scientists. Clarendon Press, Oxford, p. 153-164

Richards, F. J. (1959). A flexible growth function for empirical use. J. exp. Bot. 10: 290-300

Sanders, H. L. (1968). Marine benthic diversity: a comparative study. Am. Nat. 102: 243-282

Schnute, J. (1980). A versatile growth model with statistically stable parameters. Can. J. Fish. Aquat. Sci. 38: 1128-1140

Somero, G. N., Siebenaller, J. F., Hochachka, P. W. (1983). Biochemical and physiological adaptations of deep-sea animals. In: Rowe, G. T. (ed.) Deep sea biology. John Wiley, New York, p. 261-330

Spiess, F. N., Macdonald, K. C., Atwater, T., Ballard, R., Carranza, A., Cordoba, D., Cox, C., Diaz Garcia, V. M., Francheteau, J., Guerrero, J., Hawkins, J., Haymon, R., Hessler, R., Juteau, T., Kastner, M., Larson, R., Luyendyk, B., Macdougall, J. D., Miller, S., Normark, W., Orcutt, J., Rangin. C. (1980). East Pacific Rise: hot springs and geophysical experiments. Science 207: 1421-1433

Tunnicliffe, V., Desbruyères, D., Jollivet, D., Laubier, L. (1993). Systematic and ecological characteristics of Paralvinella sulfincola Desbruyères and Laubier, a new polychaete (family Alvinellidae) from Northeast Pacific hydrothermal vents. Can. J. Zool. 71: 286-297

Tunnicliffe, V., Garrett, J. F., Johnson, H. P. (1990). Physical and biological factors affecting the behaviour and mortality of hydrothermal vent tubeworms (vestimentiferans). Deep Sea Res. 37: 103-125

Tunnicliffe, V., Juniper, S. K. (1990). Dynamic character of the hydrothermal vent habitat and the nature of sulphide chimney fauna. Progr. Oceanogr. 24: 1-13

Venus, J. C., Causton, D. R. (1979). Confidence limits for Richards functions. J. appl. Ecol. 16: 939-947

Manuscript first received: December 3, 1992

Revised version accepted: February 24, 1993 